\title{
Vertical Cricoid Lamina Ossification: A Rare Pitfall in the Diagnosis of Extraluminal Foreign Body
}

\author{
${ }^{1} \mathrm{GM}$ Divya, ${ }^{2}$ Hasif Muhammad, ${ }^{3} \mathrm{KC}$ Ramachandran, ${ }^{4} \mathrm{~K}$ Shiji
}

\begin{abstract}
Ossification of airway cartilages on plain X-ray film may masquerade as a foreign body in the digestive tract in some patients with a history of foreign body ingestion. This process may cause confusion to the clinician, who then has to rely on other investigations and explorative surgery to exclude the possibility of an impacted or extraluminally migrated foreign body. Here we present a pitfall in the diagnosis of extraluminal foreign body impaction secondary to vertical ossification of cricoid lamina, which resulted in an explorative surgery.
\end{abstract}

Keywords: Foreign body, Upper digestive tract, CT scan, Extraluminal, Lateral pharyngotomy, Vertical cricoid.

How to cite this article: Divya GM, Muhammad H, Ramachandran KC, Shiji K. Vertical Cricoid Lamina Ossification: A Rare Pitfall in the Diagnosis of Extraluminal Foreign Body. Int $\mathrm{J}$ Head Neck Surg 2014;5(2):91-93.

Source of support: Nil

Conflict of interest: None

\section{INTRODUCTION}

Foreign body impaction in the upper digestive tract remains a frequent problem in otolaryngology practice. It is important to diagnose foreign body impaction early to prevent lifethreatening suppurative or vascular complications. Even though plain films (lateral view of the neck) play an important role in diagnosis of these foreign bodies, calcification of the posterior part of cricoid cartilage, arytenoid cartilage or posterior aspect of the thyroid cartilage can be interpreted or confused as foreign bodies. Hence, the awareness of the radiographic feature of normal laryngeal cartilage ossification and correlation with the patient's clinical presentation is important to prevent unnecessary investigation and surgery. This is a case report of a rare pitfall in the diagnosis

\footnotetext{
${ }^{1}$ Assistant Professor, ${ }^{2}$ Associate Professor, ${ }^{3}$ Professor

${ }^{4}$ Junior Resident

${ }^{1}$ Department of Otorhinolaryngology, Government Medical College, Kozhikode, Kerala, India

${ }^{2}$ Department of Anesthesia, Government Medical College Kozhikode, Kerala, India

${ }^{3,4}$ Department of ENT, Government Medical College, Kozhikode Kerala, India

Corresponding Author: GM Divya, Assistant Professor Department of Otorhinolaryngology, Government Medical College, Kozhikode, Kerala, India, Phone: 9447128285 , e-mail: omdgm@yahoo.co.in
}

of extraluminal foreign body impaction. The patient had a foreign body at the cricopharynx which was removed endoscopically and the check X-ray showed a remnant foreign body which was again confirmed by CT scan neck. A lateral pharyngotomy and neck exploration was carried out, which concluded it as vertical ossification of cricoid lamina and not remnant foreign body.

\section{CASE REPORT}

A 40-year-old gentleman presented in our department with the complaint of accidental ingestion of fish bone (head part of fish) 2 days back and thereafter persistent foreign body sensation throat. On examination his general condition was satisfactory. Vital parameters were well maintained. Throat examination was normal. Indirect laryngoscopy showed pooling of saliva in both pyriform fossae but no foreign body. Neck movements were painless but laryngeal crepitus was absent. Systemic examination was essentially normal.

In view of the positive clinical history, persistent symptoms and clinical examination findings, an X-ray of the soft tissue neck lateral view was taken. It showed an irregular shaped radiopaque foreign body at the level of C5-C6 with no significant prevertebral widening or air shadow or air fluid level (Fig. 1). An emergency hyopharyngoscopy was done under local anesthesia. The foreign body was found at the cricopharyngeal level and the surrounding mucosa was found inflamed. It was removed endoscopically and was a $1.5 \mathrm{~cm}$ sized, irregular shaped fish bone broken into

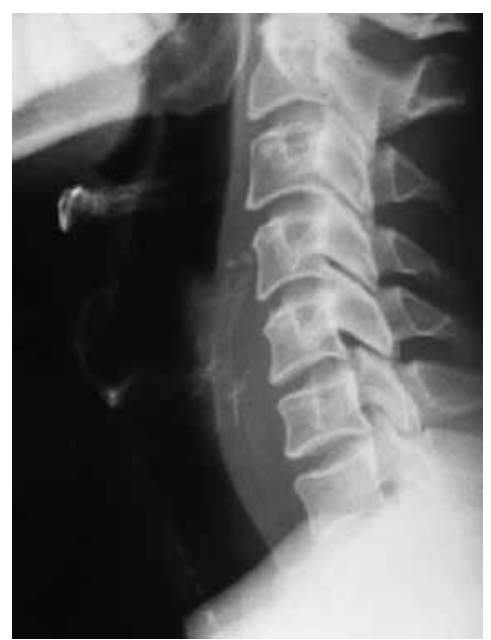

Fig. 1: X-ray soft-tissue neck lateral view showing irregular radiopaque foreign body at the level of $\mathrm{C} 5-\mathrm{C} 6$ 


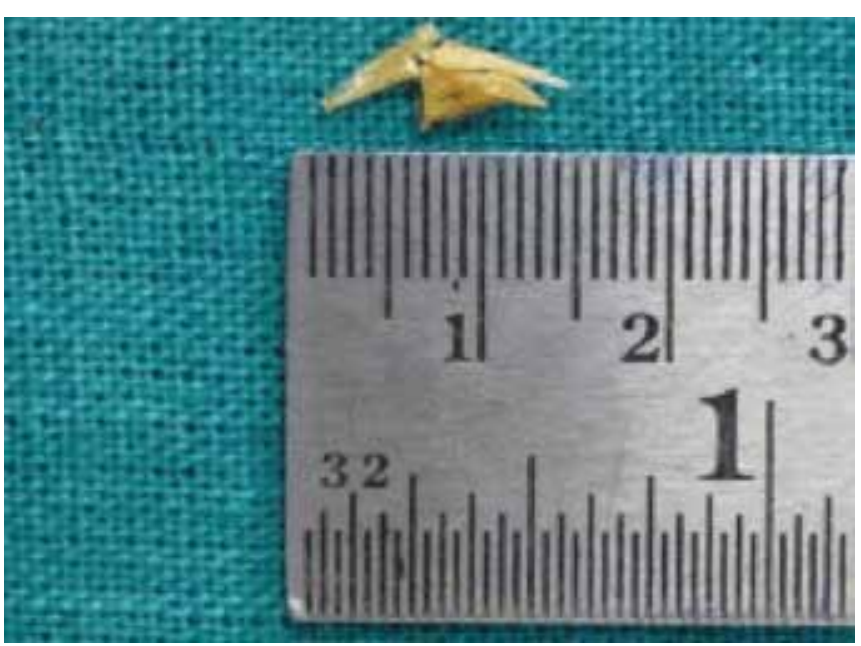

Fig. 2: $1.5 \mathrm{~cm}$ sized irregular shaped broken fish bone

two pieces (Fig. 2). As the size of the retrieved foreign body was not correlating with the size of the radiopaque shadow in the X-ray, a detailed search was done endoscopically for remnant foreign body which showed nothing intraluminally. A Ryle's tube was inserted. A check X-ray soft-tissue neck lateral view was taken and it showed a linear radiopaque shadow at the C5-C6 level just posterior to cricoid cartilage and anterior to the shadow of Ryle's tube (Fig. 3). After the endoscopy, the patient was free of foreign body sensation but started complaining of vague pain in the lower neck.

In view of the 2 days history of retained foreign body, retrieved foreign body in broken piece, persistent pain and shadow suspicious of remnant in check X-ray, a CT scan was planned. Plain and contrast enhanced CT scan neck was taken and it reported the presence of a radiopaque foreign body of length $1.2 \mathrm{~cm}$ posterior to posterior ring of cricoid cartilage at the level of C6 vertebra extraluminally (Fig. 4).

On behalf of the CT scan findings, a repeat endoscopy and proceed under general anesthesia plan was made. On endoscopy a gritty feeling suggestive of remnant foreign

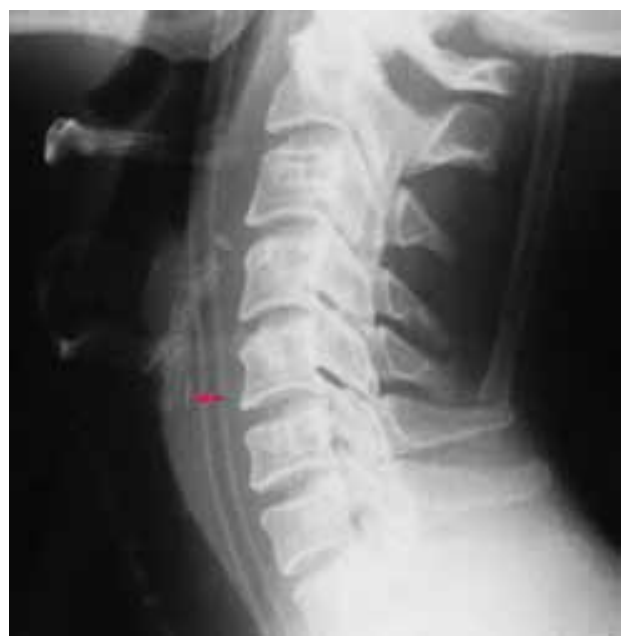

Fig. 3: Check X-ray soft-tissue neck lateral view showing a linear radiopaque shadow at the $\mathrm{C} 5-\mathrm{C} 6$ level just posterior to cricoid cartilage and anterior to the shadow of Ryle's tube body was got just underneath the posterior cricoid mucosa. Hence, proceeded with right lateral pharyngotomy and the post cricoid area were explored. No foreign body was found anywhere in that area. However, a prominent calcified ridge along the median plane of the cricoid lamina was noted and a conclusion was made that the persistent linear radiopaque shadow was actually the vertically ossified cricoid lamina.

The post cricoid mucosa was meticulously sutured using 30 ' Monocryl. The lateral pharyngotomy was closed by interrupted 30 ' Monocryl sutures. Neck wound closed after attaining hemostasis and putting a No: 12 suction drain. The patient was nil oral and was on RT feeds for 7 days. Postoperative X-ray soft-tissue neck lateral view showed the same linear radiopaque shadow which confirmed the vertically ossified cricoid lamina (Fig. 5). Pharyngeal fistula was excluded by barium study on postoperative days 7 and oral feeds were started. The postoperative period was uneventful and patient was discharged on postoperative days 8 .

\section{DISCUSSION}

Impaction of foreign body in the upper digestive tract is a common complaint in the otolaryngologic practice. Early diagnosis and removal of impacted foreign body is very important as retained foreign body can cause suppurative complications such as retropharyngeal, parapharyngeal and mediastinal abscess and vascular complications such as aortoesophageal and innominate-esophageal fistulae and carotid rupture.

Plain films (lateral view of the neck) play an important role in diagnosis of these foreign bodies as vast majority $(88 \%)$ of the foreign bodies are found to be radiopaque. ${ }^{1}$ At times ossification of airway cartilages on plain X-ray film can be interpreted or confused as foreign bodies. The awareness of the radiographic feature of normal laryngeal

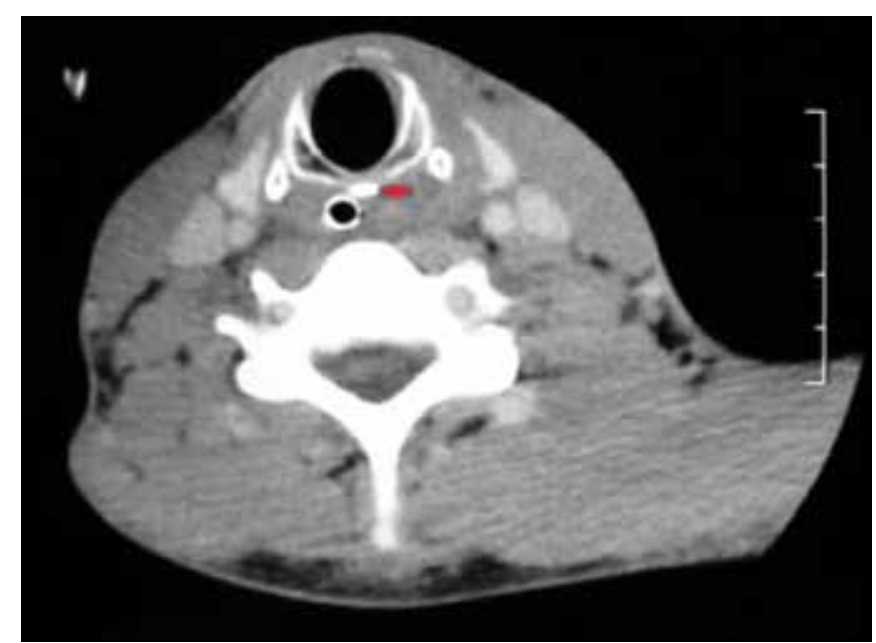

Fig. 4: CT scan of neck showing the presence of a radiopaque foreign body of length $1.2 \mathrm{~cm}$ posterior to posterior ring of cricoid cartilage at the level of C6 vertebra 


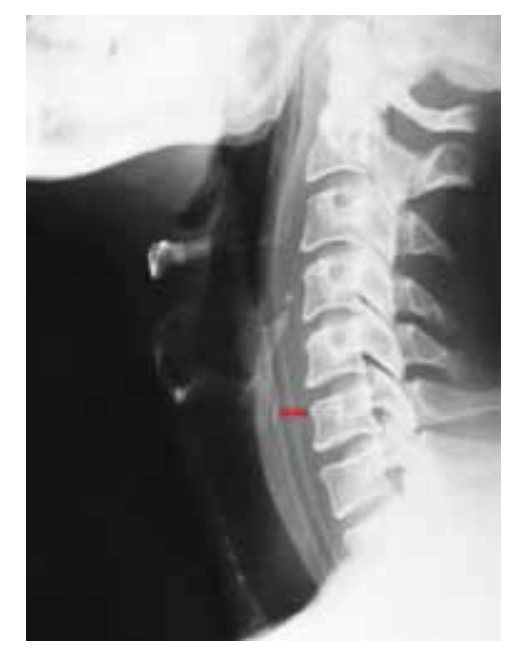

Fig. 5: Postoperative $X$-ray soft-tissue neck lateral view showing the same linear radiopaque shadow confirming the vertical ossification of cricoid lamina

cartilage ossification is very essential in the prompt diagnosis and management of impacted foreign bodies in upper digestive tract.

Ossification and calcification of the laryngeal cartilages have been widely investigated since the original study by Chievitz in $1882 .^{2}$ The thyroid, cricoid and greater part of the arytenoid cartilages consist of hyaline cartilage that undergoes calcification and ossification as part of the aging process. The terms 'calcified' and 'ossified' are often used synonymously but calcification always precedes ossification when cartilage becomes transformed into bone. ${ }^{3}$

Ossification of the cricoid cartilage begins first in the curvilinear superior border of the lamina. ${ }^{4,5}$ Separate areas of linear ossification often occur in the posterior border of the lamina and in the oblique superior border of the arch. The rest of the lamina and the posterior half of the arch usually show a hazy ossification that spreads downwards and forwards. The anterior half of the arch is the last to ossify. Two areas in the cricoid are likely to be confused with a foreign body. ${ }^{5}$ First, the superior tip of the cricoid lamina is often the only part to be ossified for some time, and because of its curvilinear appearance, may resemble a bony foreign body. Second, vertical ossification of the posterior margin of the cricoid lamina may also occur separately and mimic a bony fragment, as shown in our case. ${ }^{6}$
The radiographic feature of normal cricoid calcification should be known to prevent misdiagnosis of this condition as an impacted foreign body. The linear cricoid opacity of a physiological calcification is usually thin and never extends beyond the upper or lower cricoid borders, where as the linear opacification of an impacted foreign body may extend beyond the cricoid borders and may be irregular, depending on the shape of the foreign body. ${ }^{7}$

Although, in our case, the linear opacification was between the level of the upper and lower borders of the cricoid cartilage on plain X-ray film, findings in CT scan was highly suggestive of an impacted foreign body in the post cricoid area. The CT scan of the cricoid cartilage showed a break between the densely calcified ridge and the rest of the calcified cricoid posterior lamina (see Fig. 4), suggesting the linear opacification on plain X-ray film an extraluminal foreign body.

In our case, only by surgical exploration we could say that the persistent linear ossification was not a remnant foreign body. This case report highlights the need of awareness of the normal laryngeal cartilage ossification which may masquerade as a foreign body and results in unnecessary surgery and morbidity.

\section{REFERENCES}

1. Abdullah BJJ, Kaur H, Ng KH. Radio-opacity of malaysian fish bones: an in vitro study. Asian J Radiol 1997;3:327-338.

2. Chievitz JH. Untersuchungen uber die Verknocherung der menschlichen kehlknorpel. Arch Anat Physiol Anat Abt 1882;49: 303-349.

3. Strauss S. Sonographic appearance of cricoid cartilage calcification in healthy children. AJR Am J Radiol 2000;174:223-228.

4. Keen JA, Wainwright J. Ossification of the thyroid, cricoid and arytenoids cartilages. S Afr J Lab Clin Med 1958;4:83-108.

5. Hately W, Evison G, Samuel E. The pattern of ossification in the laryngeal cartilages: a radiological study. Br J Radiol 1965; 38:585-591.

6. Richardson GS, Albuquerque NM. Unusual calcification of cricoid cartilage masquerading as foreign body in esophagus. AMA Arch Otolaryngol 1955;62:316-318.

7. Lim CT, Tan KP, Stanley RS. Imaging case study of the month: cricoid calcification mimicking an impacted foreign body. Ann Otol Rhinol Laryngol 1993;102:735-737. 